\title{
Human-Animal Immune Simulations in Covid-19
}

\author{
Ibrahim Shnawa \\ University of Qasim, College of Biotechnology,Qasim, Babil, Iraq
}

\begin{abstract}
The theme of Human-Animal immune simulations in covid-19 is of tripartite nature.First is the human, the second is the infecting virus and the third is the animal. The simulation criteria for human are; functional immune system, evident harmony in the nervous-endocrine-immune axis, potent homeostatic mechanisms and good nutritional status. The infectious virus should be capable to; Find port of entry, did efficiently the receptor mediated entry to the target cell entrance ,production of outnumbering viral particles forming viral load, production of virulence factors and evading the host immune mechanisms. The virus first sound to be zoonotic in nature, but then it expresses anthropozoonotic and zooanthroponotic infection cycle. Human sars-cov-2 infection forms clustered in six infection forms. While in the mammalian experimental sars-cov-2 infection is mostly of mild respiratory form. The mammalian animal simulation criteria are; High percent similarity in structure and function to human immune system, similar harmony in the axis of nervous-endocrine-immune systems and evident similarity percent in the cellular events of the immune responses to that of man.Sars-cov-2 antigenic epitopes identified as spike protein epitope, nucleoprotein epitope and binding domain epitope, infection in man rise up specific antibodies as early in the immune response time curve as IgM, then class switched to IgA in acute course of the infection then lately switched to IgG in chronic state. Anti-spike antibodies are virus neutralizing parallel to recovery from the infection. The duration of antibody lasting in patient plasma around three months but their protective efficacy upon re- infection is a matter of debate. Neutralizing anti-spike protein antibodies prevents experimental reinfection in both monkeys and Syrian golden hamsters. Though the duration of such protection to experimental reinfection is rather unknown.CD4 T cells effector and memory subsets are of crucial protective role in human covid-19.CD8 T cells and NK cells are exhausted during the human acute infection form. The role of NK,CD4,CD8 T cells in covid-19 in experimental animals remained to be explored. Number of novel immune models concerns Sars-cov-2 virus in various facets of human infection remain to be performed.
\end{abstract}

Keywords: Antibody ,Covid-19 ,epitope , harmony , homeostasis , infection , Sars-cov-2 ,virus

DOI: $10.7176 / \mathrm{JBAH} / 10-18-05$

Publication date:September $30^{\text {th }} 2020$

\section{Introduction}

Phylogeny is the history of evolution of a biological species. Ontogeny ,however ,is developmental biology of an individual representing a species. Homology constitute the similarities in structure and function of an organ or organ-system .Analogy indicated similarity in function and differences in structure(Clegg 2000). The concepts behind these terms are majorly dependent on similarities and differences which forms the basics of the traditional human-animal organic evolution(Milluer 1998).A structure -function simulations between collard dove and rabbits immune system had been done by one of my doctorate students( Hassan 2002)..In continuum with these investigation, Abd (2006), A doctorate student work under my supervision onto the humeral and cellular immune simulation of human vaginitis and lapin experimental vaginitis. Algebori (2008) did an immune simulation study on skin burn infection both in man and rabbits . A couple of years later ,I came across an amazing, impressive and informative source book edited by a group of medical, veterinary medical specialists and academicians nominated as Human-Animal Medicine (Rabinowitz 2009),.Going through the text layout and the forming chapters, the reader intention autonomously paved to a distinctive chapter onto allergic conditions (Reinero et al 2009). Based upon information from that source book , a mined bearing thought arose in my head, written and published as an editorial concerning Human-animal allergology(Shnawa 2016) Recently, Shnawa et al (,2020),were investigating the simulation of knee synovial mucosal cytokine responses in natural human knee joint septic arthritis to the experimental knee joint synovial mucosal cytokine during experimental septic arthritis in rabbits .The objective of the present mini-review was to authenticate the theme of human-animal immune simulations in covid-19.

\section{The Simulation Theme}

So far animals are different as compared to man, though both of them have developed defense mechanisms, systems to combats infections and tumors. Likewise, mammalian vertebrates and man have systems specialized for threatening infections and cancers. Such systems are known as immune systems .Mammalian immune systems bear major similarities and minor differences than that of human, The simulation criteria of animal-human should focus onto; the virus patho-biological potentials and the built-in nature of the defending immune systems .The simulation criteria for the virus are; Port of entry, tissue and cellular tropism, viral load ,receptor mediated pass in to the cell, replication potency, virulence factors and the nature of the cytopathic effects. While, the simulation 
criteria for the host immune systems are;1-Harmony of nervous-endocrine-immune system functions , 2Similarities of the basic elements of the lymphoid system , 3-Presence and similarity percentages of the virus cell receptor , 4-Extent of tissue inflammatory responses , 5-Nature of humeral and cellular immune responses , 6Duration and efficacy of these immune responses towards vaccination and infectious challenges, 7-The extent of association of MHS genes with diseases and 8-Evolutionary relatedness of mammalian and human immune systems (Manning \& Turner 1976,Playfair \& Chain 2001,Blom \& Ottaviani ,2017)

\section{Human}

Human is the higher ranked mammalian primate with characteristics of developed nervous, endocrine and immune systems. So far the organismic unity is concerned human individual constitute a biological system . Such biological system contained an array of organ-systems working together in a harmony. Of which, the immune-nervousendocrine axis. In the current communication a look for human as an immune system first, then for the tripartite axis in the second place. Human immune system composed of several components like; Haemolymphoid ,lymphoid ,myeloid ,lympho-myeloid ,complement and Kinin, and series of inductive secretory immune-proteins. The functions of all of these components are encoded by the genetic component, the major histocompatibility system MHC. The basic functions of the immune system is to recognize and destroy invaders like infections and tumor growths(Abbas et al ,2015).

\section{SARS-Cov-2 Virus}

The electron micrographs that showed sars-cov-2virus morphology are being with round, elliptical or even of pleomorphic morpho-types with spherical symmetry. They are single positive stranded RNA viruses with crown like appearance due to the glycoprotein spikes on the envelope surface. The virus is sensitive to heat (to certain limits) , UV, lipid solvents like ether $75 \%$, ethanol,chlorine containing antiseptics and chloroform .The pandemic patterns noted all over the world have shown that there rough grouping into two pathotypes ; the Asian initiate mild to moderate respiratory infection form and the Europain pathotype manifested as severe respiratory infection form(Illarionov \& Pivovarova 2020).British clinician at the kings college of medicine recently found that the virus human clinical manifestations are clustered into sex disease forms. To this end sars-cov-2 might has six pathotypes. First two showed flu and fever ,one gastrointestinal, one sever level one with fatigue ,one sever level two with fatigue ,one sever level two with confusion and one sever level three, abdominal and respiratory. The biological holding of such clinical observations suggest genomic variations in-vivo within the host patients through one or more of genetic re-associations or point mutations (Sundre et al.,2020). The genome structure of the sars-cov-2 virus is single stranded RNA. Its assembly as mRNA with 5 cap and 3 tail formation. The genome has 29891 nucleotide bases e,i.30 kbs in length. This base sequence encode for 9860 amino acids. On comparing with the bat sars-like genomics it was found that of $89 \%$ similarity while human sars-cov-2 virus genomics have shown $82 \%$ similarity to bat Sars genomics. The genomics structure of the sars-cov-2 consists of six open reading frames. Transcription work through replication-transcription complex RTC organized in double membrane vesicle and via synthesis of the sub-genomic RNA sequences. Transcription termination occurs at the transcription termination regulation sequences located between the forming ORFs(Chan et al.,2013,Chen et al 2020). There are six ORFs in the virus genome, of which the ORF number two to six are encoding for structural proteins like; spike protein ,membrane protein ,envelope protein, nucleo-capsid protein, and the accessory proteins . While, the frameshift between ORF 1a and ORF 1b encodes for 16 non-structural proteins. Both of the structural and non-structural proteins are associated with virulence and pathogenic mechanisms of the virus. Spike glycoproteins composed of two subunits S1 and S2 as homo-trimer complex of the spike on the viral surface guiding them to the cell receptor.S2 subunit formed from a fusion peptide trans-membrane domain and cytoplasmic domain is highly conserved sars-cov-2 sequence with sars- cov..The trans-membrane helical segment in ORF1b encodes for two nonstructural proteins nsp2 and nsp3.Studies have indicated that that there are viral mutations in nsp2 and nsp3 of sars-cov helical segment at the position 723 glycine substituted by serine at sars-cov- 2 and at position 1010 isoleucine substituted by proline at sars-cov-2 . Such mutations possibly explains the potential disease relapse. Around fourteen proteins types were mapped in corona virus proteome(Chan et al 2019,Perman \&Netland 2009, Song et al 2018,Ageletti et al. 2020, Pennington \& Dunn 2001). The source of infection can be food born as in case of china raw food consumption habits. Besides the animal reservoir the bats and ant eaters(OIE 2020,AVMA 2020).From food or from reservoir virus shed human becomes infected and diseased. Human to human transmission is being well evident through direct contact ,droplet, common use of towels and utensils of the patients ,air born in closed settings and infected surfaces(AVMA 2020).Fancy and companion animals in closed house settings may got infection from infected human owners. Carnivores in captivity may contract infection from human giving animal care in a day life fashion. Infected carnivore in captivity niche may infect others in the same niche. Thus both zoo-anthropo-philic and anthropo-zoophlic patterns of infection are expectable and observable( OIE 2020,AVMA 2020 ,Schottau et al 2020). 


\section{Animals}

Animals are broadly subdivided into invertebrate and vertebrates. Vertebrates are consisting an array of lower and higher biological ranks, Namely, fish, amphibians, raptiles and mammals including man(Clegg.2000.Abbas et al 2015). What worth mentioning in this communication is a look to the animal-human as an immune system functioning in combating infections and tumors. The main functions of the immune system are to recognize and destroys the foreign invaders[infections and tumors]. Though at certain abnormal circumstances may destroy their own components[pathologic autoimmune responses]. The main functions of the immune systems are mostly governed by the major histocompatibility systems, homeostatic mechanisms and nutritional status as well as environmental insults. The responses of these systems are through natural[innate] ,crossroad and adaptive immune responses to the infections, vaccines, immune-therapeutics and tumors. The basic elements of the mammalian and human immune systems are with relative degrees of similarities and differences( Manning \& Turner 1996,Playfair \& Chain 2001,Blom \&Ottaviani 2017,Abbas et al 2015).

\section{Immune-Neuro-Endocrine Axis}

To combat and defend against dangers like infection, tumor invasion is a character mediated by molecules and mechanisms present in all living creatures from the simpler forms of invertebrates up to man .Such molecules and mechanisms becomes more complicate and more sophisticated in higher rank no-human and human primates. In mammalian vertebrate including man, three well developed systems involved in the reactions to external and internal stress insults, danger of; infection ,allergens and tumor invasion. These are the immune, nervous and endocrine systems. The immune system communicate[talk to each other] with the central nervous system, Table1. Such communication produced during inflammations and infections is of bidirectional nature between these two systems .Cytokines are a hormone-like peptide secreted from host immune cells have played a special role in the interaction between immune and neuro-endocrine systems. Invertebrate and vertebrate have similar defense molecules. Though in mammals including man ,the function of these molecules remains basically alike meantime evolving toward more complicated and centralized organs. The immune-nuro-endocrine system provides answers to ecologic and immunologic demands in terms of efficiency and economy. Susceptibility of disease in vertebrates encodes by the gene functions and emerges as a results of continuous dynamic interactions between the internal tissue micro-environment and the external environmental insults(Blom \& Ottaviani 2017).

\section{Animal-Human Immune System}

Broadly ,animals are categorized into an invertebrate and vertebrates. Both of these categories have their own defense mechanisms against infections and tumor growths. Though, the components ,effectors and mechanistic events are somewhat different. Vertebrate comprise fish, amphibians, reptiles ,birds and mammals. All vertebrates have the nervous-endocrine and immune system axis. The objective of this simulation looks for the immune system out of this tripartite axis. Of the vertebrate immune systems a focus was made onto that of mammals(Cooper 2003, Blom \&Ottaviani 2017) .

Mammals are grouped into three categories. First ,the protothera the egg laying mammals, second the metathera the marsupials and third , the euthera the placental mammals, Table- $1 .$. In metathera, the marsupials have short gestation period and the young off springs are born in an immature stage of development .The maturation of these young is completed through carriage in the mother pouch. Such marsupial pouch young are indispensible models for: First, the investigation on an early exposure to various exogenous antigens by the aims of detection of antigenic stimulation and cellular basic events of humeral and or cellular immune responses.Second, was for doing thymoctomy and matching its effect on the developmental immunology of these pouch young as compared to the invasive interventions needed for fetal thymoctomy for that of placental mammals. In euthera ,the gestation period is relatively longer so that permits completing the fetal organismic biological integrity so as concerning the nervous-endocrine-immune axis(Manning \& Turner 1996,Playfair \& Chain 2001).The immune system functions are mainly governed by MHS system gene families. MHS has distinct chromosomal organization that is very similar but not identical in all mammals so far examined. The structure and function of the mammalian MHS gene families is evolutionary conserved .The gene forming the MHS are extremely polymorophic with very large number of alleles .Such polymorphisim apparently has been through species diversification. Though some mammalians like whales, Syrian hamster showed little MHS polymorphism while mice and man has shown marked MHS polymorphisms. Mammalian T cells seems to be violently responding to MHS incompatible grafts as compared to that of minor histocompatibility antigens.MHS functions in restriction of ;Antigen processing by antigen presenting cells, restriction of cytotoxic and helper T cells during the events recognition of antigens by the immune cells as well as tissue compatibility during tissue transplantation and with association of some disease states. Besides encoding the immune responses. The MHS genetic system do have three classes in man and mice ,two classes in dog swine horse and rabbits, (Playfair \& Chain 2001,Newman \& Antczak, Kelin 1987, Fan et al 2019, Shiina \& Blancher 2019,Berry 2012, Darden \& Streilein 1984,Ducan \& Streilein 1977 ) . 
Table -1 : Nervous Endocrine Immune Systems Evaluation

\begin{tabular}{|c|c|c|c|}
\hline $\begin{array}{l}\text { Category(Clegg } \\
2000)\end{array}$ & $\begin{array}{l}\text { Immune- } \\
\text { nervous- } \\
\text { endocrine } \\
\text { axis( Blom \& } \\
\text { Ottaviani 2017) }\end{array}$ & $\begin{array}{l}\text { Subcategory(Clegg } \\
\text { 2000,Playfair \& Chain } \\
\text { 2001) }\end{array}$ & $\begin{array}{l}\text { Molecules and mechanisms of the immune } \\
\text { system( Playfair \& Chain 2001,Cooper } \\
\text { 2003,Seous et al 2020) }\end{array}$ \\
\hline Invertebrate & Primitive & $\begin{array}{l}\text { 4-Molluscs } \\
\text { Arthropods. }\end{array}$ & $\begin{array}{l}\text { 1-Cells use specific glycoprotein for self } \\
\text { recognition. specific aggregation } \\
\text { 2-Accept genetically identical graft ,but } \\
\text { slowly reject non-identical grafts .Some } \\
\text { evidence of specific memory } \\
\text { 3-Coelomic animals have cell specialization. } \\
\text { Earth worm contained at least four type, all of } \\
\text { them are phagocytic, but some of which are } \\
\text { specific for graft rejection and the others } \\
\text { produce; opsonins, lysins, and agglutinins } \\
\text { 4-No graft rejection, primitive alternative } \\
\text { form of complement. Insects immune system } \\
\text { own the Toll-like receptors for natural } \\
\text { immune recognition, adhesion molecules also } \\
\text { present in arthropods. } \\
\text { 5-Presence of phagocytic cells, specific } \\
\text { memory, allograft rejection, production of } \\
\text { cytokine like IL1 and TNF. Such cytokine like } \\
\text { secretion also found in other invertebrate }\end{array}$ \\
\hline Pre-vertebrate & developing & Tunicates & $\begin{array}{l}\text { Self re-newal of haemopoietic cells, the stem } \\
\text { cells, lymphoid-like cells,single MHC } \\
\text { controlling the foreign graft rejection }\end{array}$ \\
\hline Vertebrate & Well developed & $\begin{array}{l}\text { 1-Jawless fish } \\
\text { 2-Cartilagenous fish } \\
\text { 3-Bony Fish } \\
\text { 4-Amphibians } \\
\text { 5-Reptiles }\end{array}$ & $\begin{array}{l}\text { 1-The earliest } \\
\text { surviving vertebrates Lymphoid cells } \\
\text { arranged in foci. First definite four chain Ig. } \\
\text { 2-Sharks;first appearance of lymphoid } \\
\text { system ,B,T cells and typical four chain units } \\
\text { of Ig and classical complement } \\
\text { 3-Separate B and T cell functions, presence of } \\
\text { NK,IL2,IFN cytokines and polymorphic } \\
\text { MHC like that of mammals } \\
\text { 4-Lymph nodes, gut associated lymphoid } \\
\text { system ,haemopoiesis in bone marrow ,clear } \\
\text { MHC } \\
\text { 5-T cell receptors, IgM ,IgG } \\
\text { 6-Complement B component take the place of } \\
\text { C4,C2.B and T cells are separated in } \\
\text { production site. No lymph nodes, but thymus } \\
\text { are multi-lobular. } \\
\text { 7-Mammals;Ig and MHC diversity. Little } \\
\text { MHC polymorphism in whales and Syrian } \\
\text { hamsters. }\end{array}$ \\
\hline
\end{tabular}

\section{Human Pathogenesis and Pathogenicity}

The port of entry of the virus can be eyes, nostrils and mouth.From there passes to throat, bronchus then finally to lungs. Lung cell become infected .Structural and nonstructural viral proteins take part as molecular virulence factors when the intracellular viron particles exceeds the infected cell volume and production of early and late viral proteins. The lung cellular damage do happened through the action of activated immune cells producing an excessive IL6 amounts leading to the cytokine storm. A case which in turn induce immune tissue injuries in the lung tissue cellularity. Such immune events may initiate cytokine release syndrome which ultimately may terminated by multiple organ dysfunction and septic shock in the critical cases of human corona disease. The pathogenesis and pathogenicity concept of sars-cov-2 virus infected human being is relative and conditional dependent on the host health state. There found somewhat a balance paradigm .Viremia may be followed by the 
extra pulmonary manifestation of the disease. In the infected host tissue microenvironment, when the immune mechanisms, can be able to combats and balance the pathogenic effects of the sars-cov- 2 virus, the host is being with no evident symptom and no pathology. But if the overall immune mechanisms, could not established the combating of viral virulence burden, the virus then will be able to escape such mechanisms leaving the infected host being in a weak state of immune system activities( Chen et al 2020 ,Chan et al 2019 Ageletti et al 2020).

\section{Animal Pathogenesis and Pathogenicity ( OIE 2020,AVMA 2020 , Schottau et al 2020 ) \\ 9.1 Domestic Permissive \\ 9.1.1 Felines}

Domestic cat are susceptible to natural and experimental infections with sars-cov-2 and experimental transmission from infected to non-infected cat has been observed .The structure of cat ACE2 is similar to that of human .In other studies, two cats were confirmed infected with sars-cov-2 virus showing the sign of mild respiratory illness. The source of infection in one was its infected owner and in the second, from infected neighborhood in New York city.

9.1.2 Canine

The dogs being infected with sars-cov- 2 virus in more than 20 reports all over the world. The evidence till date that the source of infections are typically results from close contact with covid-19 diseased owners .

9.1.3 Minks

Four large farms of minks in Holland has been contracting natural sar-cov-2 virus infection, among which some individuals were test positive for the virus. The mink population in these farms consists of sick and healthy ones. Two cases of mink infection documented to be transmit to human.

9.1.4 Ferret

Ferrets have particular robust upper respiratory tract infection with sars-cov-2 virus. The clinical manifestation of the infection ranged from mild to severe which presented as fever and sneezing as that of human covid19. Transmission of infection is both by direct and indirect contacts.Sars-cov-2 virus bind to ACE2 receptor of the ferrets lung cells. The genetic structure of ferrets ACE2 receptor is similar to that of man. The virus are capable to replicate in the lung cells. The experimental ferret infection with this virus through nasal rout have shown mild rhinitis with prominent viral load in the upper respiratory tract and more efficient viral replication .Ferret are valuable experimental models for better understanding ; pathogenesis ,pathogenicity ,immune response events , and vaccine evaluation.

9.1.5 Monkeys

Non-human primates like monkeys are of great benefits for coronavirus studies as an infection, disease and immunity. All of the known test monkeys are found to be permissive to Sars-cov-2. Infection causing fever, pneumonitis and diarrhea. The rhesus macaque has been demonstrated permissive for sars-cov- 2 infection through ocular conjunctiva route causing transient infection and mild pneumonia,Covi-19 in older monkeys have demonstrate more severe of the infection. Hence may be valid as a model for study of ageing in relation to severity of the infection. Nonhuman primates ,ferrets and hamsters have been presumed to be potential natural hosts for sars-cov-2. While other animals like tree shrew, woodchuck, pangolin ,rat, guinea pig, and cotton mouse might be potential hosts to support sars-cov-2 infection.

\subsection{Domestic Non Permissive}

Domestic livestock animals like bovine, ovine ,caprine are either infected but passed unnoticed, unreported or they are possible non-permissive to sars-cov-2 virus. There is a little or even no evidence that these domestic livestock animals are easy infected with sar-cov-2 under natural conditions and no evidence that they are transmitting the virus to people.

\subsection{Carnivories At Captivity}

Five tigers and three lions housed in two enclosures at the Bronx Zoo in New York city. One of the five tigers test positive for sars-cov-2,the other four tigers and the three lions had developed sings of respiratory disease over the course of a week, The affected animals are long term residents of the zoo, without chronic medical conditions and no new animals introduced to the group for several years. Other large cats with clinical signs of respiratory disease were likely to be infected with sars-cov-2. The source of the infection from the zookeeper incubating the infection .

\section{Immunity}

\subsection{Human}

Sar-cov-2 virus infection in human initiate both humeral and cellular immunity. The humeral mediated by virus neutralizing, virus binding and anti-nucleoprotein antibodies and the cellular is mediated by T cells( Kirkcaldy et al 2020,Gerfoni et al , Sekine et al 2020). The neutralizing antibodies have shown variable degrees of protection on use from the convalescent sera for managing human critical clinical infection cases. The exact duration of 
humeral antibody mediated immunity is a matter of debates( Seous et al 2020,Wajnberg et al 2020).British workers on limited number of patients and single viral receptor binding domain the reach the conclusion that the duration of neutralizing antibody is of short duration with no apparent protectivity as that of common flu virus[ Kirkcaldy et al 2020). Though recent study performed in united states on large population of patients and health care workers have shown that; 1-antibody detected in natural human to sars-cov- 2 infection can be detected in most of the infected individuals 10-15 days following the onset of the symptom.,2-serocoversion rate in $95 \%$ of the patients, 3-the magnitude of the nab is dependent on the severity of the case, 4- High titred ab patients maintained levels within 60 days post infection while the low titred patients decline to the base within three months. Thus the duration of the humeral ab response is for three months .In other word protection from reinfection if any!? might lasts for three months( Gerfoni et al 2020,Sekine et al 2020). The immune response time curve have shown early $\operatorname{IgM}$ then IgA in acute phase infection, IgG class switch lately appeared within the chronic onset of the infection. The antibody responses induced by natural mild to moderate of Sars-covid-2 infections are robust neutralizing and stable for at least three months(Wajnber et al 2020), Convalescent plasma containing antibody protective effects seemed to provide attenuation of the virus on infection rather than complete protection in severe cases( Piechott et al 2020 ). The story of duration of immunity is not finished right now. Some covid-19 diseased patients either with reduced or nullified antibody response. In continuum, T cell subsets played crucial role in sars-cov-2 human infection. Currently, it was found that symptomatic ,mild and convalescent individuals exhibits robust $\mathrm{T}$ cell mediated immunity with sars-cov-2 specific memory $\mathrm{T}$ cell will likely prove to be critical in long term protection against covid-19(Sekine et al 2020).In other current study T cell responses to structural nucleo-capsid protein NP, non-structural NSP7 an NSP13 of the ORF region of the virus genome in the covid-19 convalescents. T cells CD4 and CD8 subsets recognizing multiple regions of NP proteins and the long term memory T cells reacts to sars-NP, 17 years after 2003 outbreak of sars which display robust cross-reactivity to sars-con-2 NP. Infection with beta-coronavirus induces multi-specific and long lasting $\mathrm{T}$ cell immunity( LeBert et al,2020 ).Infection of human with sars-cov-2 lead to exhaustion of the antiviral NK and CD8 T cells. Since the total numbers of T cells and NK as well as CTL in mild and severe covid-19 disease reduced as compared of normal, Such exhaustion of $T$ cells is as a consequence of sarscov- 2 infection may play a role in the pathogenesis of the disease. Thus improving the cellular immune responses early in the infection may be beneficial to viral elimination(Zheng et al 2020). Studies on the ICU critical cases have shown that spike protein specific CD4 T cells increased overtime since ICU admission .More lymphocytes became activated to peptide pool of spike protein,sars-cov-2 specific CD4 T cells were predominantly of central memory lymphocyte subsets. their activation was associated secretion of Th1 cytokines such as INF g, TNF alpha and IL2.( Weiskopf et al 2020). Thus, spike proteins have antigenic epitopes triggering B cell in direct or through TH2 cells to produce specific antibodies and other epitopes that triggers TH1 cells.Appraently,CD4 increased during infection course and produce TH1 cytokines while CD8 cytotoxic $\mathrm{T}$ cells and NK are exhausted. Both B cell and T cell immunity are eligible for protection, durability and reinfection immunity. Though the exact mechanisms for how they perform them is a matter of debate.

\subsection{Immune Features of Human Covid-19}

- The virus spike protein epitopes currently ranging as 19 epitope type. Five of which are the immunedominant. Besides the nucleoprotein epitope and the binding domain epitopes.

- Infection as it acts as a life vaccine it induces natural,cross-road, and adaptive immune responses. Spike protein epitope, binding domain epitope and nucleoprotein epitopes may activate $\mathrm{TH} 2$ leading to growth, proliferation, expansion of effector antibody producing B cells and memory B cells .In continuum, the spike protein epitope may activate TH1 cells developed into CD4 ,CD8 cell with helping and killing effects respectively. NK and CD8 cells exhausted during acute sar-cov-2 human infection.CD4 cell found increased with severity of the infection ,Table-2.

- Convalescent plasma sero-therapy to the moderate to severe cases appeared to be helpful in weakening the replication of the virus giving relief, forever protection is a matter of debate. The occurrence of convalescents re-infection still contra-versial topic

- Reliable immune-therapeutics and vaccines on the way to be developed and evaluated

- Patients of transient and nullified antibody responses still need to be urgently managed

- Animal simulating; cytokine storm induction and management ,immune mediated micro-thrombi in lung and other distant organs due to immune over-reaction, immune-compromised state infection, neonate immune responses to infection, and tumor-covid-19 infection remained to be initiated and develop. 
Table -2 : Human-Animal Infection and Immune Simulations

\begin{tabular}{|c|c|c|c|c|c|c|c|}
\hline Species & $\mathrm{MHC}$ & $\begin{array}{ll}\begin{array}{l}\text { Type } \\
\text { infection }\end{array} & \text { of } \\
\end{array}$ & Susceptibility & Clinical signs & Pathology & Transmission & $\begin{array}{l}\text { Immune } \\
\text { response/use }\end{array}$ \\
\hline Human & $\begin{array}{l}\text { MHCI,II,III, Class I,II } \\
\text { Markedly Polymorphic } \\
\text { (Newman\& Antczak } \\
\text { 1983,Kelin 1987) }\end{array}$ & Natural & Low to high & $\begin{array}{l}\text { Respiratory, } \\
\text { other five } \\
\text { forms }\end{array}$ & $\begin{array}{l}\text { Pneumonia } \\
\text {,cytokine storm, } \\
\text { Micro-thrombi }\end{array}$ & $\begin{array}{l}\text { Animal-Man, } \\
\text { Man-Animal } \\
\text { and Animal } \\
\text { to animal }\end{array}$ & $\begin{array}{l}\text { Humeral } \begin{array}{r}\text { and } \\
\text { cellular, } \\
\text { therapy }\end{array} \\
\text { plasma }\end{array}$ \\
\hline Mink & $\begin{array}{l}\text { Class I,II,III } \\
\text { Class II, extreme } \\
\text { polymorphic (Fan et al } \\
\text { 201928) }\end{array}$ & Natural & High & $\begin{array}{l}\text { Yes, none to } \\
\text { mild }\end{array}$ & Respirator & $\begin{array}{l}\text { Between } \\
\text { minks }\end{array}$ & $\begin{array}{l}\text { Humeral response, } \\
\text { infection, vaccine }\end{array}$ \\
\hline Macaque & $\begin{array}{l}\text { Mafa class I,II,III .Class } \\
\text { I } 84 \text { haplotype,II, } 16 \\
\text { haplotype(Shiina \& } \\
\text { Blancher 2019) }\end{array}$ & Experimental & High & $\begin{array}{l}\text { Mild to } \\
\text { moderate }\end{array}$ & $\begin{array}{l}\text { Lung lesions } \\
\text { similar to that of } \\
\text { man }\end{array}$ & Yes & $\begin{array}{l}\text { Humeral } \\
\text { response, infection , } \\
\text { vaccine, plasma } \\
\text { therapy }\end{array}$ \\
\hline Ferret & $\begin{array}{l}\text { Class I,II,III, } \\
\text { Class I with } 48 \text { distinct, } \\
\text { alleles (Berry 201230) }\end{array}$ & Experimental & High & Non to mild & $\begin{array}{l}\text { Rhinitis, pre- } \\
\text { vasculitis, } \\
\text { vasculitis, prebron } \\
\text { chitis }\end{array}$ & $\begin{array}{l}\text { Yes between } \\
\text { ferrets }\end{array}$ & $\begin{array}{l}\text { Humeral } \\
\text { response ,infection } \\
\text { and vaccine }\end{array}$ \\
\hline Hamster & $\begin{array}{l}\text { HMHC I,II. III. Class I } \\
\text { with two monomorphic } \\
\text { Class II, multiple } \\
\text { polymorphic [Ducan \& } \\
\text { Streilein 1977) }\end{array}$ & Experimental & High & $\begin{array}{l}\text { None to } \\
\text { moderate }\end{array}$ & $\begin{array}{l}\text { Pathology of } \\
\text { larynx and } \\
\text { Spleen }\end{array}$ & $\begin{array}{l}\text { Yes between } \\
\text { hamsters }\end{array}$ & $\begin{array}{l}\text { Humeral } \\
\text { response, infection } \\
\text { vaccine }\end{array}$ \\
\hline
\end{tabular}

\section{Animal}

The talk in this paragraph is mainly confined to experimentally infected permissive mammalian animal models including monkeys and hamsters, Table-2 ;

\subsection{Monkeys (Zimmer 2020,Bao et al 2020)}

In one of the scientific research institute involved in work on non-human primates infection and immunity .A group of workers use to infect three rhesus macaques with sars-cov-2 virus infection, follow up the infected monkeys till recovery from first exposure to the virus. A second infection initiated with the same virus. Follow up in the post infection period has shown that the re-infected monkeys did not developed signs of infection .A finding that suggest that non-human primate, monkeys are capable of developing some sort of short term immunity to this virus infection. A group of monkeys were experimentally infected nasal spray bearing sars-cov-2 virus then followed up till recovery from the initial infection. The researchers again expose the recovered monkeys to the same virus nasal challenge. The monkeys resist the second infection. In other working group at other scientific institute also performing research on infection and immunity onto the nonhuman primate. The group use to vaccinate four rhesus macaques with experimental DNA based covid-19 vaccine that holds the code for the viral protein that are needed for stimulation of the immune system. Follow up period to initiate immune response in the vaccinate monkeys. An aerosol born sar-cov-2 virus sprayed in the nostrils of these vaccinated monkeys. Monkeys did not develop infection in the post-vaccination period. In four other rhesus macaques monkeys Bao et al (2020), initiate sars-cov-2 infection in these monkeys with aim of detecting immune responses to the spike protein during one up to four weeks post-infection. Antibodies to spike protein have developed within the second week onward and lasted up to four week , the time point of termination of the observation. The monkeys recovered from infection and anti-spike protein antibodies took part in the recovery. Monkeys recovered plasma were used to other noninfected monkeys leading to protect them from infectious challenge.

\subsubsection{Immune Features of Monkeys Models}

- The infection rout and port of entry is nostrils.

- Infection form is mild mainly upper respiratory tract

- DNA based vaccine and infection induced anti-spike antibodies

- Infection, vaccination and convalescent plasma protects from re-infection with in the limits of the observation periods

- Monkeys T cells immune responses are tried to sars cov virus other than that of human.

\subsection{Syrian golden hamster( Imai et al 2020,Rogers et al 2020,UWM 2020)}

A working group were performing sars-cov-2 virus nasal infection to golden hamsters. The infected hamsters were followed up in 10,14 and 20 days post infection periods. The infected animals were divided into two parts. The first part, at the day 10 the eviscerated hamsters did not showed virus in most of the hamsters organs. The day 14 post infection, most of the eviscerated hamsters were showing lung damage. While , the day 20 post-infection all of the animal got lung damage. Animals of the day 14 post-infection onward were subjected to blood collection before evisceration to detect the presence of neutralizing antibodies .The second part were subjected to second round of infection. follow up of the second round of infection animals did not became sick and evisceration studies failed to detect the virus in the respiratory organs of the re-infected animals. All of the infected and recovered 
hamsters produce antibodies and not re-infected so it suggest that they develop immunity that protect them against re-infection. But still not indicate the duration of such protection.

11.2.1 Immune Features of Hamsters

- Infection rout and port of entry is nostrils.

- The infection is respiratory form mild, moderate and sever depends on the duration of observation post infection. At the day 14-20 lead to lung tissue damage.

- Infection induce humeral anti-spike protein antibody response.

- Recovery lead to protection from reinfection with suggested role of antibodies for protection

\section{The Immune Simulations Outcomes}

One of the common senses in immune-biology of infectious diseases is that similarity is of degree and does not mean identity and the immune simulations of covid-19 is not an exception to this common sense( Saif \& Jung 2020). The immune-biology of covid-19 is of rather complex nature( Kirkcaldy et al 2020 ). Digging through , reforming, reframing and editing the information concerning the covid-19 current literature(Kirkcaldy et al 2020, Gerfoni et al ,Seous et al 2020, Wajnberg et al 2020,Saif \& Jung 2020) ,besides the collective experience in immunology of infectious disease(Hassan 2002, Abd 2006 ,Algebori 2008 ) lead to the following immune simulation outcomes;

- Permissive-sity [Host range] to sars-cov-2 virus infection ranges from; Man , monkeys, ferrets ,minks, $\mathrm{dog}$, cat and hamsters. Though in some it is natural but in other it is experimental.

- Six infection forms were recently reported in man(Sundre et al 2020), but it is mostly reported as respiratory in the observed mammals(OIE 2020,AVMA 2020,Schottau et al 2020).In addition to asymptomatic virus carriers(Bia et al 2020).

- Immunity to sars-cov-2 infection in man and mammalian animals is both of humeral and cellular nature( Sundre et al 2020 ,Gerfoni et al,Seous et al 2020,Wajnberg et al 2020). but in mammalian animals cellular immune response wait to be explored(Zimmer 2020,Rogers et al 2020).

- llama produce two type of antibodies to sars-cov-2 virus(Wrap et al 2020).

- The immune response is of tripartite arms the natural[innate],cross-road , and adaptive both in man and placental mammals permissive to sar-cvo-2 infection( Wajnberg et al 2020 Zheng et al 2020).

- Human antibody in severely infected patient have shown to be of multi-epitopic nature ranging up to 19 epitope (Liu et al 2020).

- Some human covid-19 disease patients either does not produce antibody or transient short time difficult to be detected(Kirkcaldy et al 2020) but it does not reported neither in natural nor in experimental mammalian models due to small population size available to experimentation inferred by economic or management insults(Imai et al 2020,Zimmer 2020).

- Permissive-sity [Host range] to sars-cov-2 virus infection ranges from; Man, monkeys, ferrets ,minks, dog, cat and hamsters. Though in some it is natural but in other it is experimental.

- Six infection forms were recently reported in man(Sundre et al 2020), but it is mostly reported as respiratory in the observed mammals(OIE 2020,AVMA 2020,Schottau et al 2020).In addition to asymptomatic virus carriers(Bia et al 2020).

- Immunity to sars-cov-2 infection in man and mammalian animals is both of humeral and cellular nature( Sundre et al 2020 ,Gerfoni et al,Seous et al 2020, Wajnberg et al 2020). but in mammalian animals cellular immune response wait to be explored(Zimmer 2020,Rogers et al 2020).

- llama produce two type of antibodies to sars-cov-2 virus(Wrap et al 2020).

- The immune response is of tripartite arms the natural[innate],cross-road , and adaptive both in man and placental mammals permissive to sar-cvo-2 infection( Wajnberg et al 2020 Zheng et al 2020).

- Human antibody in severely infected patient have shown to be of multi-epitopic nature ranging up to 19 epitope (Liu et al 2020).

- Some human covid-19 disease patients either does not produce antibody or transient short time difficult to be detected(Kirkcaldy et al 2020) but it does not reported neither in natural nor in experimental mammalian models due to small population size available to experimentation inferred by economic or management insults(Imai et al 2020,Zimmer 2020).

- Sero-therapy with convalescent plasma is of help for weakening the replication of the virus and attenuate its pathogenic vajor for the favor of the patient(Myoclinic Staph 2020) but its protectivity from reinfection remain to be confirmed (Rogers et al 2020,Zimmer 2020).

- Post infection antibody responses lasted up to three months in man[Wajnber et al 2020) but experimental mammals examined seemed to be short. The immune protective efficacy to reinfection was proved in mammalian models though of unknown duration(Imai, et al. 2020,Zimmer,2020).

- Scientific bodies , manufacturing companies and state institutes all over the world are in day by day covid- 
19 vaccine race which is which be in forefront winning the race of developing the first safe, immunogenic and efficient vaccine(Shnawa,2020).

- Monoclonal antibody immunotherapy trends(Anonymous 2020) and vaccine strategies[Shnawa 2020] are on the way of production, evaluation and release to patients use.

\section{Conclustions}

Defense against Covid-19 both in man and animals imply molecules and mechanisms expressed by the infected host whether man or animal. Simply organized living animal creatures expresses simpler means of defense, from the simpler to more complicated life forms, the defense systems becomes more sophisticated and built-in well developed organs .Man and placental mammals developed well organized nervous-endocrine-immune systems. In which immune and nervous system have bidirectional communication .Cytokine a hormone like peptide produced by the immune cells affecting the endocrine system function .Both MHC genes and the emerging nervousendocrine-immune harmonic communications are affecting the susceptibility to infection.. The immune mechanisms in covid-19 in man and mammals are similar but not identical. Natural human and mammalian experimental sar-cov-2 infection induces humeral and cellular immune responses. But the cellular responses in experimental mammals still needs to be explored. Convalescent plasma therapy valid for natural human and experimental mammalian infection. Though protection and duration of immunity given by the convalescent plasma to the cases in questions is rather unclear. Cases of natural covid-19 in man with transient or nullified antibody response indicate involvement of cellular immunity, how?, the situation need to be investigated. Novel animal immune models needed to be developed in order to understand several aspect of covid -19 disease primary for the favor of saving life of human mankind.

\section{Acknowledgment}

I wish to thank my son Hamza Shnawa, BSC chemical engineer due to his help in format the manuscript.

\section{References}

Abd,F.G.(2006).Study of Some Immunological Parameters in Human And Rabbit Having Escherichia coli K1.Ph.D.Thesis, College of Science, Babylon University, Iraq.

Abbas,A.K.,Lietchman,A.H.\&Pillai,E.S.(2015).Cellular And Molecular Immunology, $8^{\text {th }}$ ed. Philadelphia ,ELSeviers-Saunders. Chapters 1-3.

Ageletti,S.,Benovento,D.,Giovanntti,M.\& Pascari, H.S.(2020).Covid-19 The Role of nsp2 and nsp3 and its Pathogenesis .Journal of Molecular Virology.11,1-10.

AL-Gebori,H.S.(2008). Some Aspects of Local And Systemic Immunity To Associated Bacteria with Skin Burns. Ph.D. Thesis ,College of Science, Babylon University ,Iraq.

Anonymous,(2020).How the Laboratory Animals are Playing a Critical Role Against covid-19 Pandemic in Developing Potential Treatment And Potential Vaccine.Tecniplast.it>update.Covid-19.

AVMA,(2020).Sars-Cov-2 in Animals ,Animal Health Welfare.

Bao,L.,Deng,W.,Gao,H.,Xiano,C.,Liu,J. et al.(2020).Reinfection could not Occur in Sars-cov-2 in Rhesus macaque.BioRxv.dio:10.1101/2020/3/13.990226.

Berry,J.(2012).Identification of Shared Major Histocompatibility Complex In Domestic Ferret. MSC .Thesis ,Biological Science, California State University.

Bia ,Y. ,Yao ,L., Wei, T.,Tian,F.,Jin,D-Y. et al.(2020).Presumed Asymptomatic carrier transmission of Covid19.Journal American Medical Association.232(14), 1406-1407.

Blom,J.M.C. \& Ottaviani, E.(2017).Immune-Neuro-Endocrine Interactions. Medical Science Moniter Basic Research,23,362-367.

Chan,J.F.,To,K.K.,Tse,H.,Jin ,D,Y,\&Yuen,K.Y.(2013).Interspecies Transmission And Emergence of Novel Viruses .Lesson From Bats And Birds .Trends in Microbiology.21:544-555.

Chan,J.F,,Kok,K.H.,Zhu,H.,To,K.K.,Yuan,S.\& Yuen,Y.(2019).Novel Human Pathogenic Virus Isolated from Patients with Atypical Pneumonia After Visiting Whuhan. Emerging Microbial Infection.9,221-236.

Chen,Y.,LiuQ.,\&Guo,D.(2020).Emerging Coronovirus: Genome Structure, Replication, and Pathogenesis. Journal of Medical Virolology.92,418-423.

Clegg, C.J.(2000),Introduction To Advanced Biology,London: John Murray, London ,Chapter 21.

Cooper,E.L.(2003).Comparative Immunology. Integrative Comparative Biology,34,278-280.

Darden,A.G.\& Strelein,W.(1984).Syrian Hamster Express Two Morphotypes Class I Major Histocompatibility Complex Molecules.Immunogenetics.20(6),603-622.

Ducan,W.R.,\& Strelein,W.(1977).Analysis of Major Histocompatibility Complex In Syrian Hamsters, Journal of Immunology., 118,832-839.

Fan,Z.,Zhang,H.,Meng,D,,Yu,Z,Jiang,L.\&Jiang,P.(2019).Molecular Cloning and Bioinformatic Analysis of DQA gene from mink[Neovision vision].International Journal Molecular 
Science.20,1037;dio.10.3390/ijms.200510371,1-14

Gerfoni,A.,Weiskopf,D.,Ramizer,S.I.,Smith ,D,M.,Crotty,S.\& Sette, A.( 2020 ).Target of T cell responses to sars-cov-2 coronovirus in humans with covid-19 disease and un-exposed individuals.Cell.181,1489-1501.

Hassan,A.J.(2002).Comparative Study On Some Aspects of The Immune Systems of Collard Dove[Streptopelia decaocta], and Rabbit[Oryctolagous cuniculus].Ph.D. Thesis. College of Science, Babylon University ,Iraq.

Illarionov,A., \& Pivovarova,N.(2020).Two Supertypes of coronavirus,East Asian and European .Cato ,At Liberty ,Cato Press ,Cato Institute,May.8.2020.

Imai,M.,Iwatsuki-Horimoto,K.,Hatta,M.,Loebrs,S.\& Halfmann,P.J.(2020).Syrian Hamster as a Small Animal Model for sars-cov-2 infection and counter measure development. Proceeding National Academy of Science. 117(8), 16587-16595.

Kirkcaldy,R,D.,King,B.A.,\&Brooks,J.T.(2020).Covid-19 and post infection immunity, Limited Evidence ,Many Remaining Questions.AmericanMedicalAssociation,323(22),2245-2246.

Klein,J.(1987).Origin of Histocompatibility Complex Polymorphism: Trans-species Hypothesis .HumanImmunology, 19,155-162.

LeBert,N.,Tan,A.T.,Kunasegaran,K.,Tham,C.Y.L., Hafezi ,M. et al.( 2020 ).Sars-Cov-2 Specific T Cell Immunity in cases of Covid-19 and Sars and un-infected controls. Nature .Com, doi, org/10,1038/s41581z.1-4.

Liu,L.,Wang,P.,Nair,M.S.,Yu,J., Rapp,M. et al.(2020).Potent Antibodies Directed to Multiple Epitopes on Sarsco-2 Spike ,Nature,July-22-2020.doi.org/10.1038/s41586-020-2571-7.

Manning,M.J,\& Turner ,R,J.(1976).Comparative Immunobiology,London .Blackie. Chapter

Millur, W.E.G.(1998),Molecular Evolution: Evidence for Mono-phyly of Meta-zooa, Germany .Springer, Chapter 1

MyoClinic Staph.(2020).Convalescent Plasma Therapy.Care At Myo -Clinic foundation for Medicinal Education and Research. Educational Pamphlet.

Newman,M.J.\& Antczak ,D.F.(1983).Histocompatibility Polymorphism In Domestic Animals .Advance of Veterinary Science And Comparative Medicine.27,1-75.

OIE(2020).Infection with Sars-Cov-2 In Animals.: Aetiology ,Epidemiology ,Diagnosis, Prevention and Control. Fact Sheet,Jun.2020

Pennington,S.\&Dunn,M.J.(2001).Proteomics :From Protein Sequence To Function. UK .Bios .

Perman,S.\&Netland,J.(2009).Coronovirus ,Past-Sars ,Update on Replication and Pathogenesis. Nature Reviews Microbiology, 7,439-450.

Piechott,V.,Chai,K.L.,Valk,S,J.,Doree,C.,Monsef,I. et al.(2020).Plasma from People who Covid-19 to Treat Individuals with Covid-19,Cochrane.National Institute of Health,Wiley.

Playfair,J.H.L.\&Chain,B.M.(2001).Immunology At A Glance. $7^{\text {th }}$ edtion, UK .Black Well Scientific .Chapter 3.

Rabinowitz,P.M.,\& Conti, L.(2009),Human-Animal Medicine, 1 ist ed.,Saunders.

Reinero, C.N. Mitchechell, C.S. ,Rabinowitz,P.M.\& ,Conti L (2009),Allergic conditions ,In, Rabinowitz P M,Conti L eds,Human-Animal Medicine, $1^{\text {st }}$ ed,Saunders, Chapter 7.

Rogers,T.F.,Zhao,F.,Huang,D.,Beutler,N.,Burns ,A.\&He,W-T. ,et al.(2020),Isolation of Potent Neutralizing Antibodies and Protection from Disease in Small Animal Model. Science; eabc 7520.Doi:101126/Science $a b c 7520$.

Saif,L.J.,\&Jung,K.(2020).Comparative Pathogenesis of Bovine and Porcine Respiratory coronavirus in Animal Host Species and Sars-cov-2 In Humans.Journal of Clinical Microbiology.58(8),eo1355-20.

Schottau,K.,Rissmann,M.,Graaf,A. Schon,J.,Sehl,J.,et al.(2020).Sars-cov-2 in Fruit bats ,Ferrets ,Pigs and Chicken :An Experimental Transmission Study. Lancet, com/microbe,july. 7.2020.

Sekine,J.,Perez-Potti,A.,Rivera-Ballesteros,O.,Starlin,K.,Gorin,J-B., et.al.(2020) ,Robust T Cell Immunity In Convalescent Individuals with Asymptomatic or mild Covid-19 or Mild Covid-19.,BiRixv.Doi.Priprint,Doi org.29-6-2020.

Seow,J.,Graham,C.,Merrick,B.,Acros,S.,Steel,K.J.A.et.al.(2020).Longitudinal Evaluation and Decline of Antibody Responses in Sars-cov-2 infection. MedRxiv Preprint .Doi-org/101101/2020/7/9,the Copy right Holder is the Author, founder, who has granted MedRxiv a License to Display the preprint perpetually, It is made available under a cc-By-NG 4 international license.

Shnawa ,I.M.S.(2020).Vaccine Race, Vaccine Immunity and Vaccine Herd Immunity.Clinical Medical Investigation.5,1-4.

Shnawa ,I.M.S,(2016).Human-Animal Allergology;Synopsis And Invitation ,Otolaryngology Open Access Journal ,1(1),000101.

Shnawa,I.M.S.,Aljanabi, I.A.A.,AL-Mohana,A.A. ,Bousis,H.A.\&Abiaes A.A.(2020).Functional Lapin-Human Simulation of Knee Joint Synovial Mucosal Cytokine Responses in Staphylococcus aureus Septic Arthritis,InternationlJournal of Public Health Research and Development, 11(3), 1242-1247.

Shiina ,T,\& Blancher A.(2019).The Cynomologus Macaque MHC Complex Polymorphism In Experimental 
Medicine.Cell.8(9),978.

Song,W.,Gui,M.,Wang,X.,\&Xiang,Y.(2018).Cryo-EM structure of Sars coronavirus spike glycoprotein in complex with Host Cell ACE2.Plos.Pathology,e100723.

Sundre, C.H.,Lee,K.A.,Lochlainn,M.N.,Varsavisky,T.,Murray,B et al.(2020),Symptom Clusters In Covid-19;A Potential Prediction Tool from the Covi-19 Symposium Study, A preprint non-peer reviewed paper,medRxiv doi.org/101101/2020.6.12.20129058.

University of Wisconson-Madison.(2020).Hamster Develop Protective Immunity in Covid-19 and are Protected by Convalescent Sera. Science Daily.22 Jun 2020.

Wajnberg, A., Amanat, F.,Firpo, A. ,Altman. D.R.,Bailey,M.J. et al.(2020),Sars-cov-2 Infection induces Robust ,Neutralizing Antibody Responses that are Stable at Least for Three Months .medRxiv preprint doi:https//doi.org 101101/2020/7/14.2051126,this preprint posted july 17/2020. The copyright of this preprint the author, founder, who, has granted medRxiv a license to display the preprint perpetually. All rights revised.

Weiskopf,D.,Schmitz,K.S.,Raadsen,M.P.,Girfoni,A.,Okba,N.M.A. et al.(2020),Phenotype of Sars-cov-2 Specific $\mathrm{T}$ cells in Covid-19 Patients with Acute Respiratory Distress Syndrome, preprint med Rxiv, org/content/101101/2020/4/11.20062349vi full pdf.

Wrap,D.,Vlieger, De.,Corbett,K.S.,Schepens,B.,Saelens,X. \&McLellan,J.S.(2020).Structural Basis of Potent Neutralization of Betacocronoviruses by Single-Domain Camelid antibodies.Cell.181,1004-1016.

Zheng ,M.,Gao,Y.,Wang,G.,Song,G.,Liu,S. et al.(2020).Exhausion of Antiviral NK and CD8 T cells in Sarscov-2 infection.Immunopedia.org.za.

Zimmer, K.(2020),Monkeys Develop Protection Antibodies to Sars-cov-2.The Scientist,March.17. 